Article

\title{
Steady-State Water Drainage by Oxygen in Anodic Porous Transport Layer of Electrolyzers: A 2D Pore Network Study
}

\author{
Haashir Altaf ${ }^{1}$, Nicole Vorhauer ${ }^{1, *(D)}$, Evangelos Tsotsas ${ }^{1}$ and Tanja Vidaković-Koch ${ }^{2}$ \\ 1 Institute of Process Engineering, Otto von Guericke University, 39106 Magdeburg, Germany; \\ haashir.altaf@ovgu.de (H.A.); evangelos.tsotsas@ovgu.de (E.T.) \\ 2 Electrochemical Energy Conversion, Max Planck Institute for Dynamics of Complex Technical Systems, \\ 39106 Magdeburg, Germany; vidakovic@mpi-magdeburg.mpg.de \\ * Correspondence: nicole.vorhauer@ovgu.de; Tel.: +49-391-67-51684
}

Received: 12 February 2020; Accepted: 19 March 2020; Published: 21 March 2020

\begin{abstract}
Recently, pore network modelling has been attracting attention in the investigation of electrolysis. This study focuses on a 2D pore network model with the purpose to study the drainage of water by oxygen in anodic porous transport layers (PTL). The oxygen gas produced at the anode catalyst layer by the oxidation of water flows counter currently to the educt through the PTL. When it invades the water-filled pores of the PTL, the liquid is drained from the porous medium. For the pore network model presented here, we assume that this process occurs in distinct steps and applies classical rules of invasion percolation with quasi-static drainage. As the invasion occurs in the capillary-dominated regime, it is dictated by the pore structure and the pore size distribution. Viscous and liquid film flows are neglected and gravity forces are disregarded. The curvature of the two-phase interface within the pores, which essentially dictates the invasion process, is computed from the Young Laplace equation. We show and discuss results from Monte Carlo pore network simulations and compare them qualitatively to microfluidic experiments from literature. The invasion patterns of different types of PTLs, i.e., felt, foam, sintered, are compared with pore network simulations. In addition to this, we study the impact of pore size distribution on the phase patterns of oxygen and water inside the pore network. Based on these results, it can be recommended that pore network modeling is a valuable tool to study the correlation between kinetic losses of water electrolysis processes and current density.
\end{abstract}

Keywords: pore network model; drainage invasion; pore size distribution; porous transport layer; electrolysis

\section{Introduction}

With innovations in the energy sector and a need for clean fuel, research is in progress to exploit the potential of hydrogen as an efficient energy source. Exemplarily, fuel cells can utilize hydrogen to produce electricity, and it can also serve as a fuel for internal combustion engines [1]. For the production of hydrogen, electrolyzer technology serves as a very promising and viable option. The purity of the produced hydrogen can be almost 100 vol \% [2]. This way, it can be integrated with other renewable resources to offer a broad range of ecologically clean methods for hydrogen production [3-5]. Shortly, electrolyzers and fuel cells will be able to help alleviate the effects of fossil and nuclear fuel consumption $[2,6,7]$. This, however, implies efficient performance of electrolyzers.

A trade-off between the production rates and the efficiency of an electrolyzer is still to be met. For this technology to be commercial, the cost and hence the efficiency needs to be optimized. Among the 
electrolyzer technologies, polymer electrolyte membrane (PEM) electrolyzers have an edge over the other varieties because of high energy efficiency and compact design [8-10]. Power needed for the electrolyzer operation can be obtained from renewable sources too and such systems have also been gaining a lot of attention recently [11]. Polymer electrolyte membrane electrolytic cells (PEMECs) are very common when coupling the technology with other renewable sources like solar or wind energy.

High current densities are necessary in order to obtain high production rates. The problem is that the high current density operation results in a decrease of electrical efficiency. This is for example, reported in [12-16] and it is mainly explained with the kinetic losses associated with the mass transfer resistances through the porous transport layers (PTL) [17]. The counter-flow of the two phases causes hindrance against each other, and this mass transfer resistance causes a decrease in the overall electrolyzer performance $[18,19]$.

It is strongly assumed that the high oxygen production rates achieved at the high current densities allow for the formation of gas bubbles that can invade the PTL and partially drain the water $[20,21]$. The size of gas bubbles increases with the increase in current density $[12,15,22]$. This leads to the formation of gas fingers penetrating the PTL from the anode catalyst layer, where the oxygen is produced, to the water supply channel from where the oxygen is removed [8]. The development of these gas fingers obviously results in the reduction of the overall water loading of the PTL. This can severely affect the water permeability, especially if the surface saturation of the PTL with water is significantly reduced by gas-filled pores [23]. On the other hand, the efficiency of the oxygen transport in the opposite direction depends mainly on the tortuosity of the evolving gas branches.

According to the work done by Suerman et al. [24], 25\% of the total cell overpotential could be contributed to the mass transport losses and these losses are mostly credited to the oxygen withdrawal from the catalyst surface and the PTLs. Yigit et al. [25] reported that at current densities less than $0.7 \mathrm{~A} / \mathrm{cm}^{2}$, the hydrogen production rates were very low and at values above $1 \mathrm{~A} / \mathrm{cm}^{2}$ the electrical efficiency decreased. Larger pores or high porosity values could easily mitigate this mass transport problem on the side of the gas phase, but it would also decrease the electron transport and affect the efficiency [8]. In contrast, small porosity values would hinder the gas removal and increase the entrapped water amount within the catalyst layer, and thus, decrease the rate of reaction [8]. For this purpose, current research aims at the structural optimization of PTLs with respect to efficient mass and electron transfer.

Various experimental methods [12,14-16,20,26-28] and modeling approaches [29-33] are already established to analyze the key factors of the PTL, such as flow regimes, structure, porosity, pore size distribution (PSD), permeability, corrosion resistance, and electrical conductivity. From these studies, the mass transfer limitations discussed before are generally either assigned to the flow regimes of the gas phase (e.g., in Dedigama et al. [12] and Zhang et al. [34]) or to the structure of the PTL. The latter has been studied in $[14,15,26,29]$ (Table 1). In Ito et al. [15] an experimental study on a $27 \mathrm{~cm}^{2}$ PEM electrolyzer cell was presented that investigates the influence of porosity and pore diameter. In this study, Ti-felt and Ti-powder prepared PTLs with different porosities and different pore structures were used. According to this study, the optimum pore diameter would be $10 \mu \mathrm{m}$, whereas no significant effect was seen for a porosity value greater than $50 \%$. Grigoriev et al. [14] estimated an optimum value of $12-13 \mu \mathrm{m}$ and $30 \%-50 \%$ as the optimum value of porosity using polarization curves for Ti-sintered PTLs with different properties. Findings presented in Kang et al. [26] in an experimental study based on thin/well tunable PTLs in a conventional cell suggested high porosity values and small pore sizes. Ojung et al. [29] used a semi-empirical model in their investigations to study PEM cell without flow channels. They varied pore sizes between 5-30 $\mu \mathrm{m}$. They observed a decrease in performance at $5 \mu \mathrm{m}$ and greater than $11 \mu \mathrm{m}$ there was no significant improvement shown by their model. They also concluded that in a system without flow channels, porosity would not influence the performance at fixed pore diameter and an optimum value of $60 \%$ was observed. Hwang et al. [35] also showed with the experiments on reversible fuel cells using Ti-felt that for mean pore sizes around $30-50 \mu \mathrm{m}$ porosity is an insignificant factor. 
Table 1. Study of the interrelation of mass transfer limitations and porous transport layers (PTL) structure.

\begin{tabular}{cccccc}
\hline $\begin{array}{c}\text { Reference } \\
\text { No. }\end{array}$ & $\begin{array}{c}\text { Type of } \\
\text { Material }\end{array}$ & $\begin{array}{c}\text { Technique } \\
\text { Used to Study }\end{array}$ & $\begin{array}{c}\text { Estimated } \\
\text { Optimum Pore } \\
\text { Size }\end{array}$ & $\begin{array}{c}\text { Estimated } \\
\text { Optimum } \\
\text { Porosity }\end{array}$ & $\begin{array}{c}\text { Operated } \\
\text { Current } \\
\text { Density }\end{array}$ \\
\hline$[14]$ & Ti-sintered & Experimental & $12-13 \mu \mathrm{m}$ & $30-50 \%$ & $0-1.0 \mathrm{~A} / \mathrm{cm}^{2}$ \\
\hline$[15]$ & $\begin{array}{c}\mathrm{Ti}(\mathrm{felt}+ \\
\text { sintered) }\end{array}$ & Experimental & $10 \mu \mathrm{m}$ & $<50 \%$ & $0-2.0 \mathrm{~A} / \mathrm{cm}^{2}$ \\
\hline$[26]$ & $\begin{array}{c}\mathrm{Thin} / \text { well-tunable } \\
\mathrm{Ti}\end{array}$ & Experimental & $400 \mu \mathrm{m}$ & $70 \%$ & $0-2.0 \mathrm{~A} / \mathrm{cm}^{2}$ \\
\hline$[29]$ & $\mathrm{Ti}$ & $\begin{array}{c}\text { Semi-empirical } \\
\text { model }\end{array}$ & $5-11 \mu \mathrm{m}$ & $60 \%$ & $0-5.0 \mathrm{~A} / \mathrm{cm}^{2}$ \\
\hline
\end{tabular}

Besides this, explanations for the structure dependence of the electro activity can also be derived from the consideration of flow regimes. Dedigama et al. [12] studied the flow regime within the PTL using electrochemical impedance spectroscopy (EIS) and thermal imaging. They found a reduction in the mass transfer limitation when passing from the bubble to the slug flow regime. In agreement with that, Zhang et al. [34] observed a decrease in the efficiency with an increase of the mass flow rate of water. Aubras et al. [31] showed that the porosity of the anode PTL affects the non-coalesced bubble regime. According to this study, higher porosity can enhance coalescence of oxygen bubbles and increase the performance of electrolyzer. Han et al. [36] also showed an increase in performance linked to an increase in porosity. In addition to that, more recent studies $[33,37]$ revealed the importance of the interaction of the two involved hierarchical porous structures at the anode electrode, namely the PTL and the catalyst layer. Exemplarily, it is demonstrated by Lee et al. [37] using micromodel experiments that the pore sizes control the burst velocity of gas resulting in the application of a thin, low porosity region at the inlet in order to reduce the gas saturations in the PTL.

The majority of the data suggests that a relatively lower value of pore size (around $10 \mu \mathrm{m}$ ) is favorable and no significant conclusion can be drawn about the porosity value. Some authors suggest a high porosity value but others suggest that higher porosity would result in a slug flow, which can lead to inefficient mass transfer and a decrease in efficiency. On the contrary, coalesced bubble regime is also suggested to enhance the performance. In our view, other properties besides mean pore size and porosity might influence the invasion process more significantly. In this paper, we aim at approaching open questions by means of pore network (PN) modeling. In detail, we will consider the role of PSD, which has a higher significance for the invasion in PTL than porosity.

From the above discussions, it can be concluded that advanced manufacturing processes are required to tune the PTL performance. The reader may refer to [26,38-40] for various examples of PTL production techniques that optimize the structure in terms of electrical efficiency and also in terms of material consumption and costs. According to Lettenmeier et al. [39] vacuum plasma spraying can be used to manufacture a PTL with a gradient in pore size along the thickness. It is possible to obtain an average pore size of $10 \mu \mathrm{m}$ close to the bipolar plate and $5 \mu \mathrm{m}$ at the electrode side, with the help of this technique (Figure 1). This coating technique can also be used to alter other properties of the PTLs suiting to the need. In a very recent study, Lee et al. [33] showed the effect of porosity gradient on the performance of the electrolyzer. The low porosity region was towards the membrane side and the high porosity region on the water inlet side (Figure 1). They observed high water permeation despite high oxygen saturations. Mo et al. [38] used electron beam melting (EBM) to mitigate the cost and manufacturing issues of the PTL. They showed $8 \%$ improvement in the performance compared to the conventionally woven PTLs. They obtained smooth surfaces at both ends of the PTL, thereby reducing the contact resistance between PTL and catalyst layer. Schuler et. al. [41] verified this impact of the interface between PTL and the catalyst layer clearly in their work. 
a.

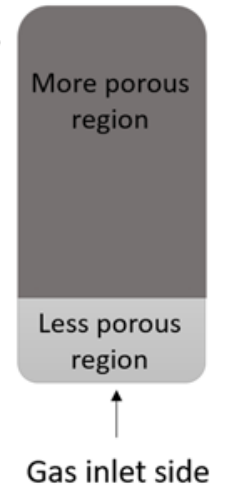

b.

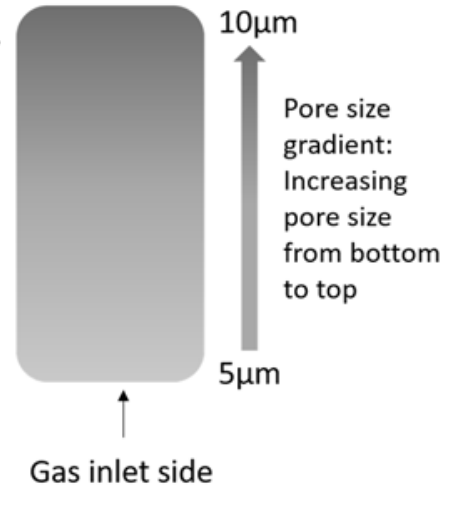

Figure 1. (a) Schematic representation of different porosity regions in PTL as studied in [33]. (b) Pore size gradient within PTL as in the study from [39].

\section{Pore Network Models}

The available methods for studying two-phase flow can be divided into continuum and discrete models. The continuum models are usually formulated for macroscale continuous phases employing effective parameters and are thus not suitable for explaining the discrete processes that occur at pore scale. So, in order to gain a deeper understanding of the invasion processes under the action of capillarity, viscous or gravity forces, pore scale models are usually preferred. Pore network models (PNMS) are a type among various pore scale models available, e.g., Lattice Boltzmann models which are mostly available on the scale of one pore. PNMs are discrete models that represent the pore space by a lattice of pores and throats (e.g., [42-46]). In comparison to other methods, which are computationally more expensive in terms of discretization of the physical domain and solving of the governing equations, PNMs can be used to study larger systems computationally more efficiently. Besides fundamental physical studies, PNMs are also used for the parameterization of macroscopic models, e.g., to predict the capillary pressure curve, relative permeability curves, as well as saturation curves [46].

PNMs are generally distinguished between quasi-static and dynamic models [47]. For the simulation of the steady-states in capillary-dominated applications [33,48-51], quasi-static models are used. In the absence of dynamic effects, e.g., driven by viscous forces, the entry capillary pressure of pores and throats controls the displacement of liquid (drainage) or gas (imbibition) in such applications [52]. In this work, the quasi-static model from [46] is applied for the simulation of the drainage of water by oxygen.

The objective of this study is to achieve a fundamental understanding of gas and liquid transport within the PTLs and the pore structure dependence of the invasion patterns. A regular 2D network of pores and throats is used to illustrate the porous PTL. The void space of this network comprises of spherical pores and cylindrical throats. Invasion percolation rules for quasi-static capillary invasion are employed to simulate the displacement of water by oxygen. The displacement mechanism is controlled by the capillary pressure curves of water that are obtained from the Young-Laplace equation:

$$
P_{l}=P_{a t m}-\frac{2 \sigma \cos \theta}{r}
$$

where $P_{l}$ is the liquid pressure, $P_{a t m}$ is the atmospheric pressure, $\sigma$ in $\mathrm{kg} \mathrm{s}^{-2}$ is the surface tension, $\theta$ is the wetting angle, and $r$ is the radius of the channel.

Invasions or displacements occur when they are energetically more favorable. More clearly, the pressure difference between the wetting fluid (water) and the non-wetting fluid (oxygen) leads to the formation of a curvature with a radius depending on the pressure difference. In the case of drainage, the non-wetting phase is the one with higher pressure to be forced through the porous structure. 
The incremental increase of the pressure inside the gas phase results in the invasion of the liquid filled pores and throats, with liquid pressures depending on their radius and wettability (Equation (1)). This means, that the stepwise invasion of the interconnected pore space results in the formation of distinct invasion patterns that depend on the PSD and the connectivity of pores and throats.

In such networks, the porosity can be increased basically in two ways, namely by (i) increasing the number of throats of the same dimensions, and (ii) changing the distribution of the throat sizes (Figure 2). In the example illustrated in Figure 3, porosity and mean throat diameter are kept constant and only the distribution varies following the invasion pressure curve computed using Equation (1). As can be seen, the differences in the structural organization of the PN are expected to result in different overall liquid saturations and different gas-liquid distributions [53]. The larger pores and throats are invaded by the gas phase while the smaller ones remain liquid saturated.

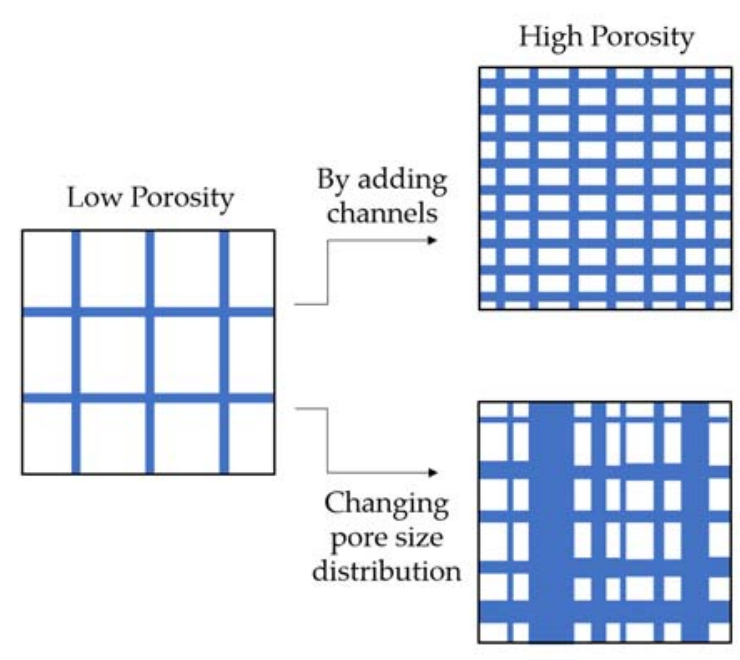

Figure 2. Different throat size distributions with same porosity but different mean throat diameter and standard deviation of the throat size. Solid in white and liquid saturated void space (i.e., pores and throats) in blue.
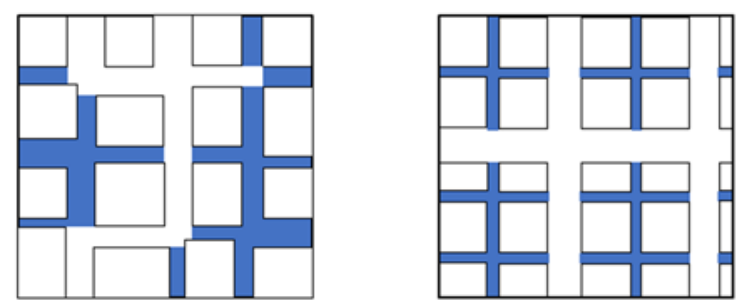

Figure 3. Different saturations for constant porosity and constant mean throat diameter but different organization of the pore network (PN). Solid and empty pores and throats in white and liquid saturated pores and throats in blue.

\section{Model Description}

The model is comprised of two parts; part one includes the determination of the data structure for the definition of the geometry of the void and solid space, and the second part contains the equations of the drainage algorithm and the cluster labeling (Figure 4). The data structure contains the information about the connections between the pores and throats in the network (Figure 5). This information is used in the drainage algorithm for the stepwise calculation of the successive invasion. The Hoshen-Kopelman algorithm $[54,55]$ is then applied to identify invading and isolated liquid clusters. 


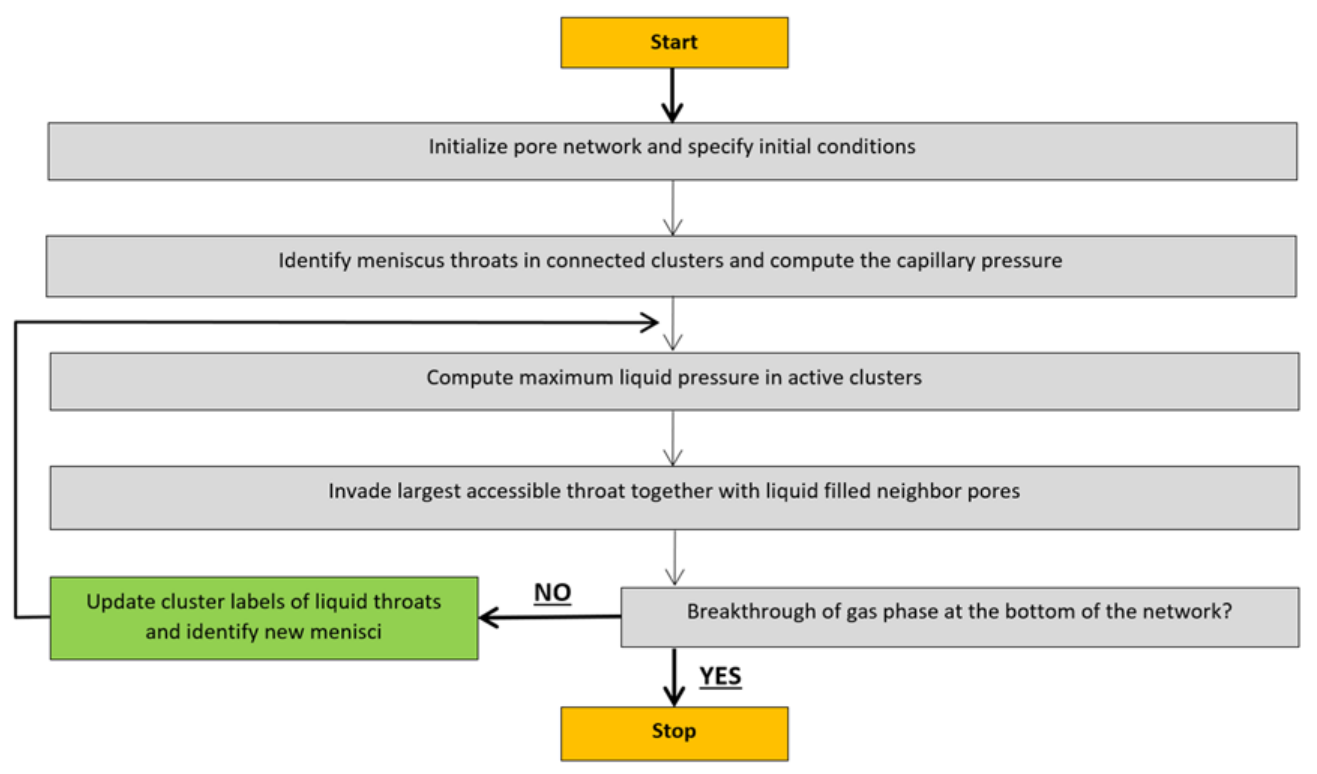

Figure 4. Scheme of the algorithm.

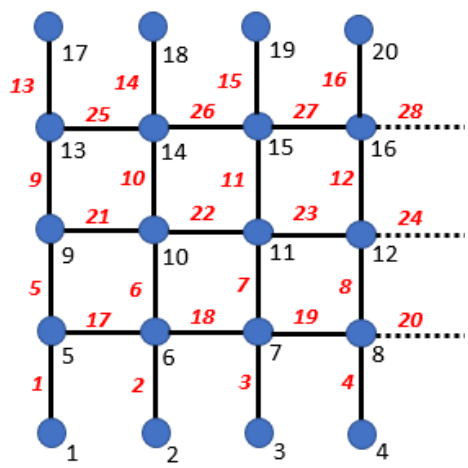

Figure 5. Pore and throat numbering in a $2 \mathrm{D} \mathrm{PN}$. The dashed lines illustrate the periodicity at the lateral boundaries.

\subsection{Network Generation}

Pore and throat radii $\left(r_{p}, r_{t}\right)$ are randomly distributed around a given average value with defined standard deviations. The geometrical arrangement of throats and neighbor pores with the relevant geometry parameters is illustrated in Figure 6.
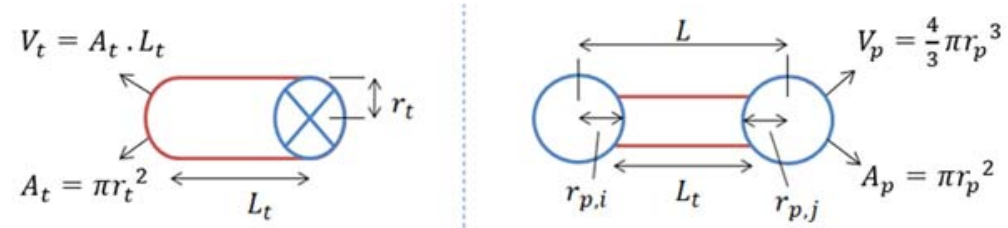

Figure 6. Geometric information about pores and throats.

\subsection{Invasion Algorithm}

After the geometric parameters are specified, active, i.e., invading clusters with their menisci are identified and the maximum liquid pressure is computed within the active clusters using Equation (1). The algorithm then selects the largest accessible throat or pore for gas invasion following the rules specified in Vorhauer et al. [46]. As invasion proceeds, entrapped clusters are formed, which are permanently isolated due to the incompressibility of the fluids. 


\subsection{Cluster Labeling}

During this process, labeling of liquid clusters is used to identify the pores and throats that are connected to each other and form a pathway for liquid and gas transport. At the start of the invasion process, the network is completely occupied by liquid, and there is only one cluster spanning the whole network and conducting the liquid phase. With initiation of invasion, numerous liquid clusters can form that are distinguished into liquid-conducting clusters (connected to bottom and top side of the PN) and isolated clusters. The Hoshen-Kopelman algorithm $[54,55]$ is used for the labeling of these clusters. Clusters are reviewed and relabeled after each invasion step to update the connections between the pores and throats.

\subsection{Model Assumptions}

1. Quasi-static drainage invasion in the capillary dominated regime.

2. PN initially saturated with water.

3. No phase transition occurs.

4. Oxygen is injected at the top side and water is removed from the bottom side.

5. There is no mixing or diffusion between the two phases.

6. Viscous, gravity and liquid film flow are neglected.

7. Piston type throat invasion computed based on the Young-Laplace equation.

8. No further invasion occurs after breakthrough of the gas phase.

\section{Pore Network Simulation of Microfluidic Experiments}

A pore and throat network was conceived using the parameters of microfluidic experiments from Arbabi et al. [20]. The PNM was constructed based on the image data extracted from Figure 7. The experimental image in Figure 7 is then used to compare the flow path of gas within the micromodel qualitatively with our own simulation results. In Figure 7, gas pores and throats are highlighted in blue (pores) and yellow (throats) while liquid pores are in red and liquid throats in black. In this investigation, we are interested if the PNM introduced above is able to predict the experimentally estimated invasion path. It is remarked that invasion is dictated by the interface curvature of pore and throat menisci, wherefore the pore and throat sizes are of interest here. They were determined from the experimental image and transferred into the data structure of the PNM. Although the pore sizes are significantly larger than the throat sizes in this example, pore invasion pressures were not matched with the pore sizes. Instead the pore sizes were randomly adjusted. As can be seen below, the simulation leads already to a very good agreement of the results. However, in a future study, it would be preferable to track experimentally the different invasion pressure thresholds of pores and throats based on the interface curvature of liquid menisci.

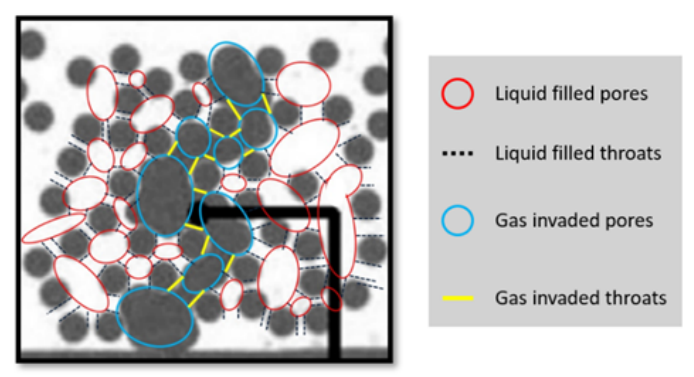

Figure 7. Microfluidic drainage experiment from Arbabi et al. [20] (Reprinted with the permission from Elsevier, 2014). Solids and gas invaded area in black, liquid in white. The PN is identified by the circles and throats. The image shows the steady-state invasion pattern after breakthrough of the gas phase from inlet (at the bottom) to water channel (at the top). 
The data of pore and throat sizes was implemented in the PNM to compute the successive invasion of the PN. The result of the simulation is shown in Figure 8. It is observed that the invasion pattern simulated with the PNM is identical with the experimental image (Figure 7). The perfect agreement reveals the suitability of the model structure and model assumptions and the ability of PNMs to predict the quasi-static drainage patterns. Though, in a future study it would be of interest, if also the stepwise invasion of the PN can be accurately predicted, not only for idealized 2D structures but also in larger and more realistic 3D structures.
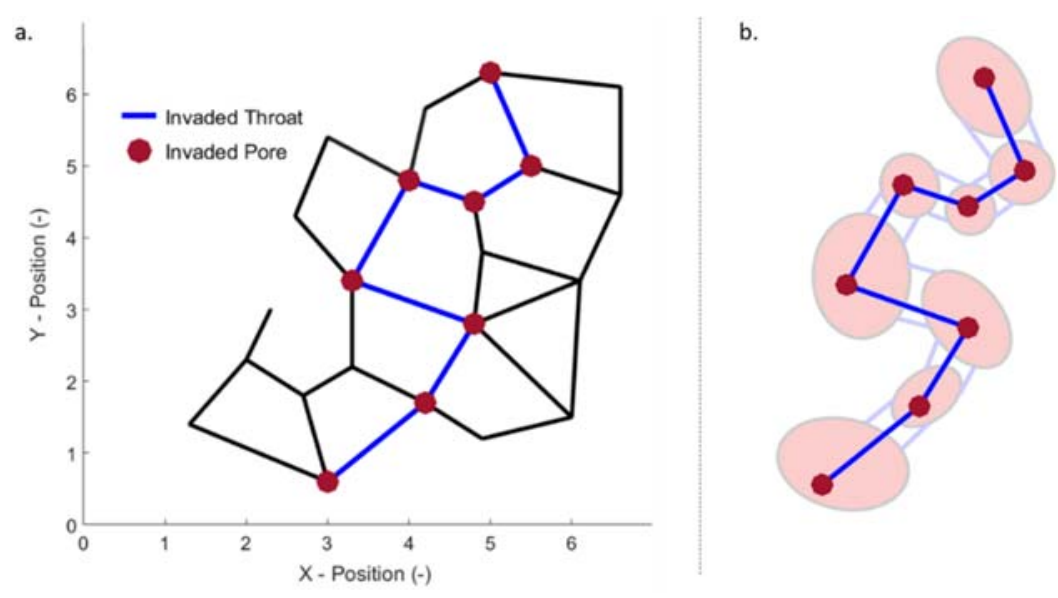

Figure 8. (a) PNM simulation result, (b) invasion pattern comparison of simulation and experiment result. Liquid-filled throats are shown in black, invaded pores in red, and invaded throats in blue. Liquid-filled pores are not shown.

\section{Monte Carlo Simulations}

\subsection{Impact of Pore Size Distribution in Monomodal PNs}

The pore size properties of sintered PTL were used to study the effect of PSD on the invasion patterns and the steady-state saturation of the PTL at breakthrough of the gas phase. For this purpose, a pore network $(\mathrm{PN})$ with the properties summarized in Table 2 were used.

Table 2. Simulation Parameters.

\begin{tabular}{cc}
\hline Parameter & Value \\
\hline Network size (columns and rows) & $80 \times 30$ \\
\hline Temperature & $80{ }^{\circ} \mathrm{C}$ \\
\hline Contact Angle & $60^{\circ}$ \\
\hline Surface Tension of water & $0.0627 \mathrm{~N} / \mathrm{m}$ \\
\hline Avg. pore diameter & $23 \mu \mathrm{m}$ \\
\hline Avg. throat diameter & $17 \mu \mathrm{m}$ \\
\hline Lattice spacing & $50 \mu \mathrm{m}$ \\
\hline Avg. throat length & $27 \mu \mathrm{m}$ \\
\hline Porosity & $63 \%$ \\
\hline
\end{tabular}

The standard deviation values were varied from $0.5 \mu \mathrm{m}$ to $3 \mu \mathrm{m}$ for a mean throat size of $17 \mu \mathrm{m}$ (Figure 9), and pore sizes were used with a constant standard deviation value of $2 \mu \mathrm{m}$. Monte Carlo simulations were done for each data point so that the given gas saturation values in Figure 10 and Table 3 are an average of 20 simulations. In general, it is observed that the final gas saturation increases at breakthrough with widening of the radius distribution. 


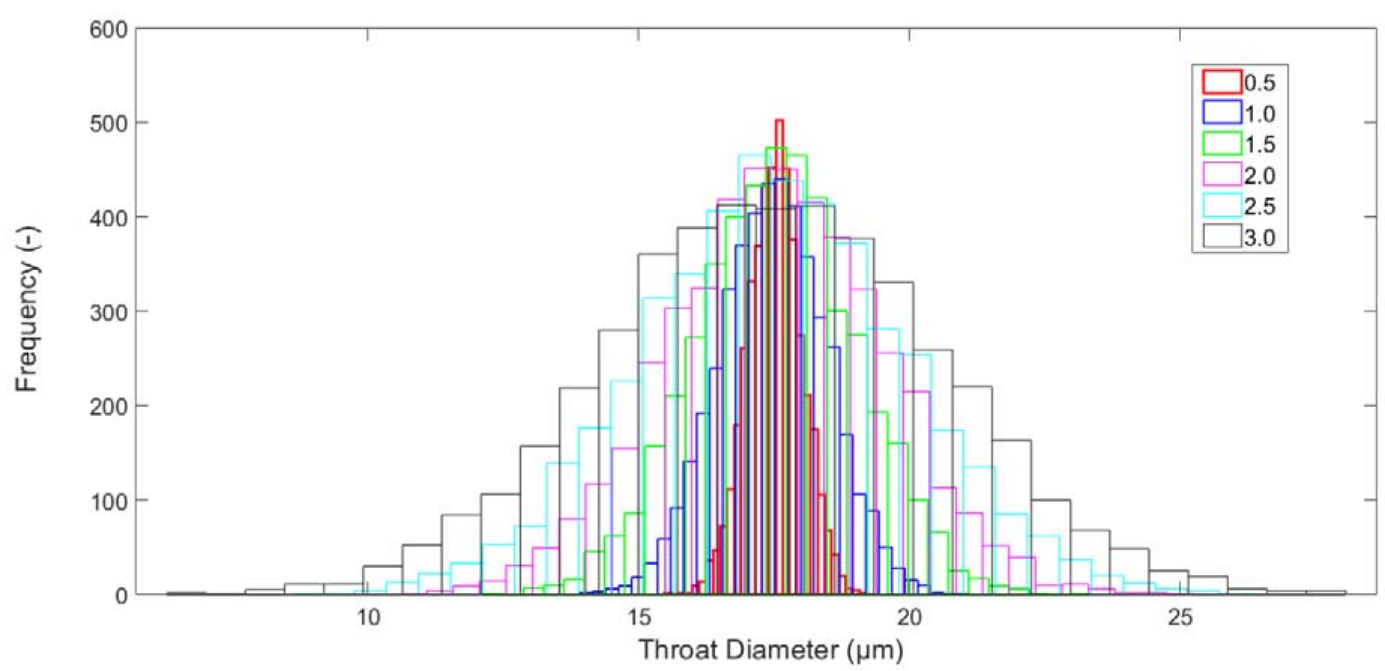

Figure 9. Histograms of pore size distribution (PSD) with varying standard deviation in $\mu \mathrm{m}$ as indicated in the legend.

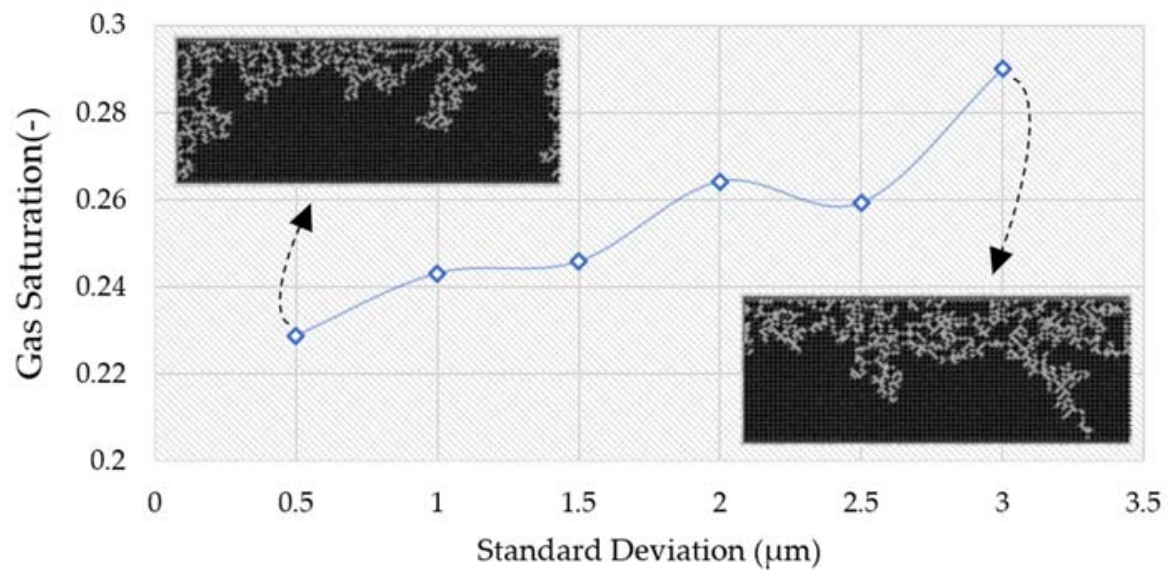

Figure 10. Gas saturation at breakthrough of the gas phase for different PSDs. The mean value of throat sizes is $17 \mu \mathrm{m}$.

Table 3. Total void volumes and porosities associated with the gas saturation at breakthrough.

\begin{tabular}{ccccccc}
\hline Standard Deviation & $\mathbf{0 . 5} \boldsymbol{\mu m}$ & $\mathbf{1 . 0} \boldsymbol{\mu m}$ & $\mathbf{1 . 5} \boldsymbol{\mu m}$ & $\mathbf{2 . 0} \boldsymbol{\mu m}$ & $\mathbf{2 . 5} \boldsymbol{\mu m}$ & $\mathbf{3 . 0} \boldsymbol{\mu m}$ \\
\hline Breakthrough gas saturation (\%) & 22.9 & 24.3 & 24.6 & 26.4 & 25.6 & 29 \\
\hline Porosity (\%) & 63.01 & 63.05 & 63.06 & 63.13 & 63.14 & 63.21 \\
\hline Total Void Volume $(\mu \mathrm{L})$ & 0.0178 & 0.0179 & 0.0180 & 0.0185 & 0.0191 & 0.0194 \\
\hline
\end{tabular}

The simulation results clearly reveal the impact of PSD on the final distribution of liquid and gas phase. While the average throat size was kept constant, the porosity of the PN increased slightly with increasing standard deviation of throat sizes (Table 3). Thus, following the literature discussions summarized above, it might be anticipated that higher porosities at constant mean throat or pore sizes are a result of an increasing standard deviation of pore and throat sizes in the referenced situations. As shown in Figure 10 and further analyzed below, the variation of PSD affects the invasion and thus the gas saturation. In detail, a higher gas saturation is obtained for broader PSDs. It is to be noted that higher PSDs than presented here can only be studied with a greater mean value of the throat size as will be discussed below. 


\subsection{Bimodal Pore Size Distributions}

The previous results analyze the influence of the PSD on the example of monomodal PNs, i.e., only one peak in the histograms in Figure 9. As can be seen from Table 3, the porosity is only marginally affected in these cases. Due to this, the phase distribution patterns change only slightly in Figure 10. In reality, pore structures often obey bimodal PSDs, i.e., with two peaks in the histogram (Figure 11) and with much stronger impact on porosity. The influence of macro pores is highlighted in Figure 3.

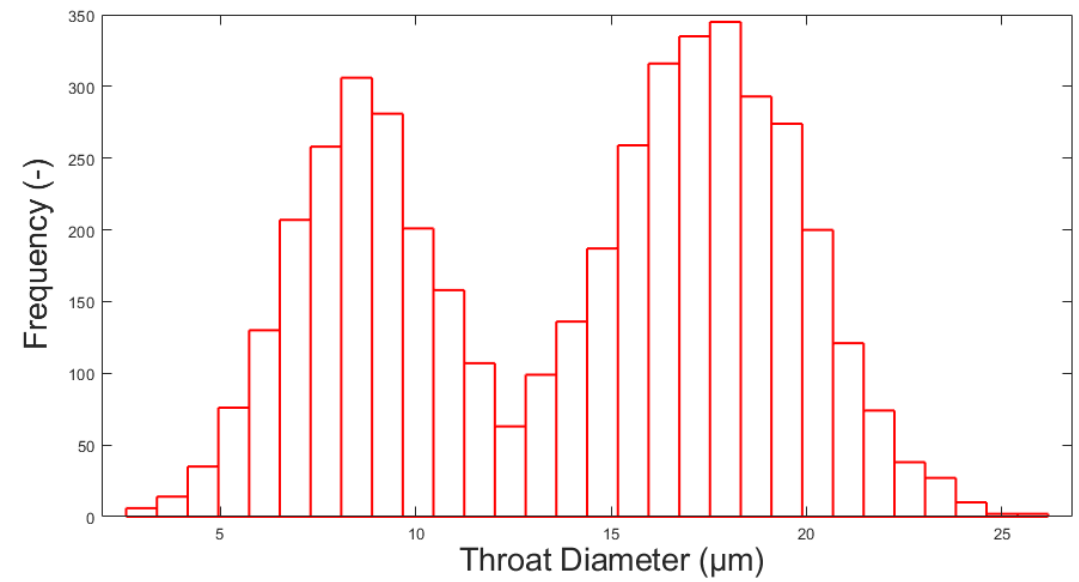

Figure 11. Bimodal throat size distribution with standard deviation $2.0 \mu \mathrm{m}$ for smaller (the first peak) and $2.5 \mu \mathrm{m}$ for larger (the second peak) throats.

As can be seen, for the monomodal PN in Figure 12, widespread invasion patterns with a high number of invasions is not achieved. This is in contrast to the bimodal PN in Figure 13. Monte Carlo simulations yielded an average gas saturation of $26 \%$ for the monomodal network and $38 \%$ for the bimodal network. This shows that widening of the PSD (Figure 9) and the introduction of macro pores (Figure 11), both, result in a change of the invasion process. This change is more significant in the second situation. While capillary fingering with narrow single gas branches is rather favored by narrow PSDs, widening of the invasion front with higher gas saturations is obtained by larger PSDs, and larger porosities. However, it can also be shown that the widening of the front can also be achieved when the porosity is kept constant and only the PSD is adjusted (Figure 13). The monomodal and bimodal networks used in simulations have a constant porosity of $71 \%$. Figures 12 and 13 also show the saturation profiles of these simulations. They reveal the importance of the consideration of the PSD for characterization of the invasion process.

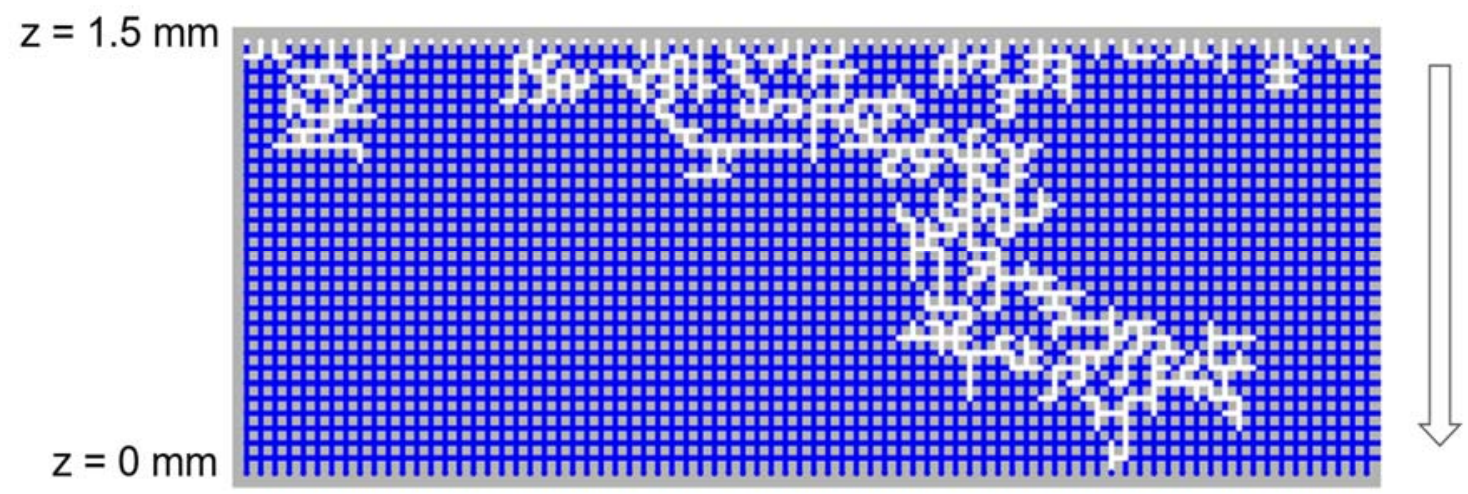

(a)

Figure 12. Cont. 


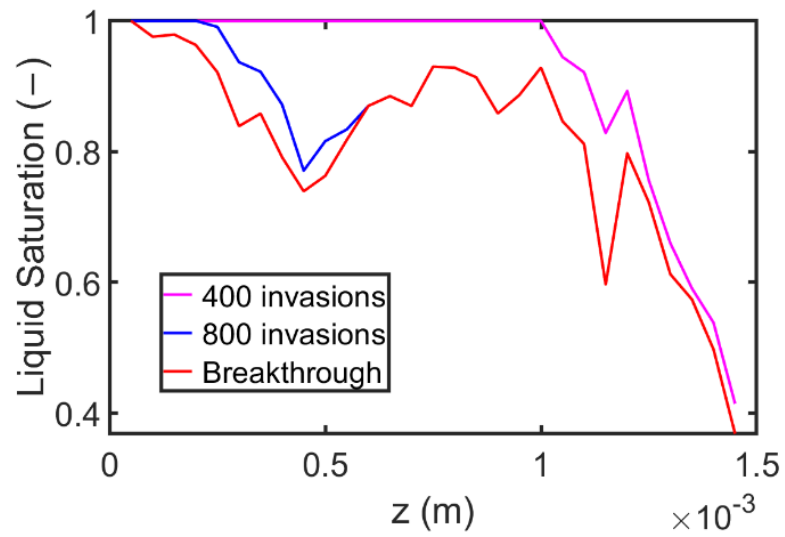

(b)

Figure 12. (a) Exemplary invasion patterns of the monomodal PN with porosity $71 \%$. Liquid in blue, gas in white and solid in gray. The arrow indicates the direction of gas invasion. (b) Saturation profiles for different overall number of invaded throats and pores achieved during one drainage simulation of the PN with randomly distributed pore and throat sizes.

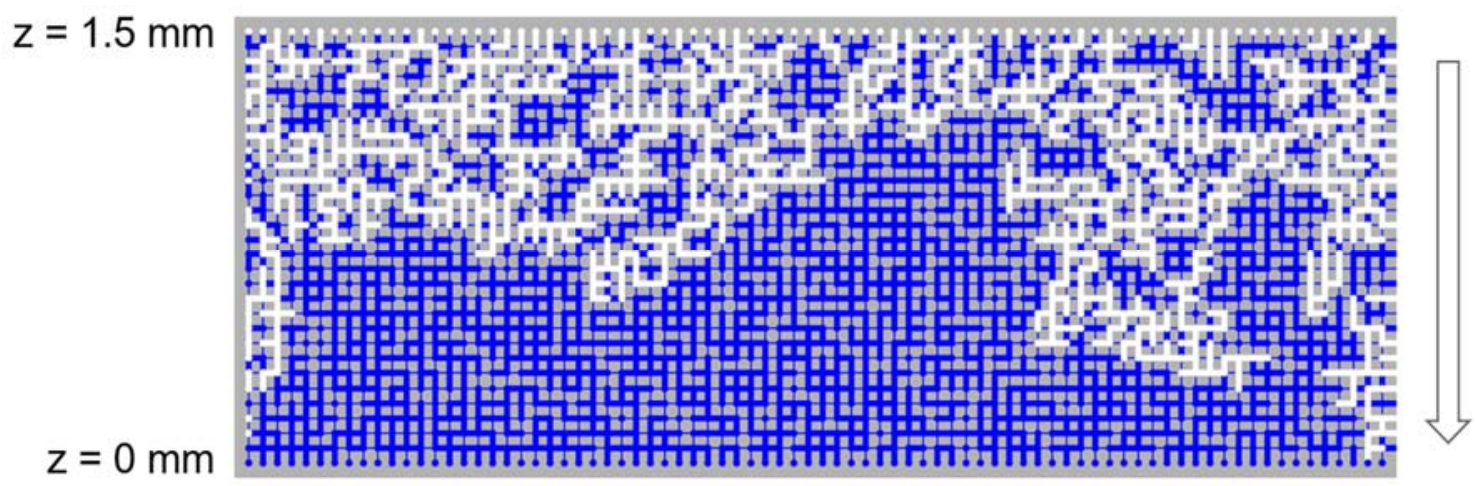

(a)

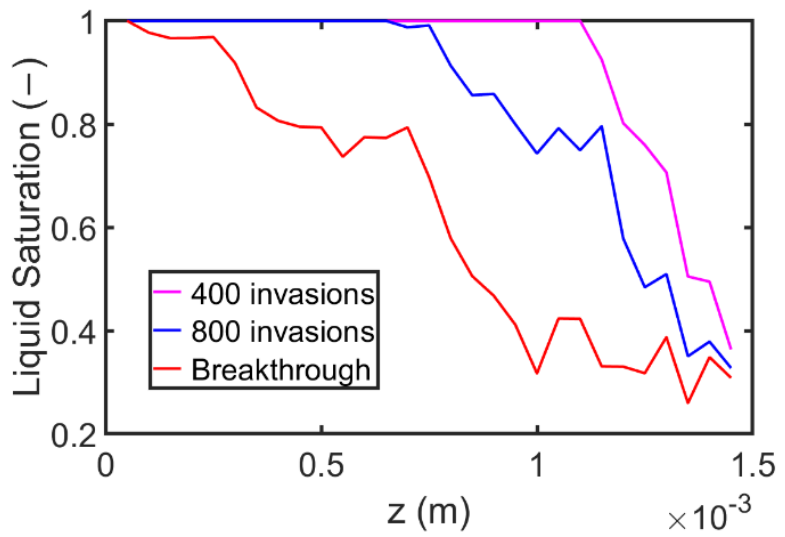

(b)

Figure 13. (a) Exemplary invasion patterns of the bimodal PN with porosity $71 \%$. Liquid in blue, gas in white and solid in gray. Macro-pores are represented by thicker lines. The arrow indicates the direction of gas invasion. (b) Saturation profiles for different overall number of invaded throats and pores from one drainage simulation.

These findings are in very good agreement with literature predictions on drainage invasion regimes [48,56,57]. According to [57], the invasion occurs in the capillary dominated regime, i.e., with 
rather low injection rate and negligible viscous forces in both fluids. The viscosity ratio of water/air is around 50, and the capillary number is calculated from the ratio of viscous over capillary forces:

$$
C a=\frac{\Delta P_{l}}{\Delta P_{c}}
$$

with liquid pressure difference $\Delta P_{l}$ and capillary pressure gradient $\Delta P_{c}$. It depends on the viscosity of the liquid phase $\eta$, the wetting curvature by means of surface tension $\sigma$, and the velocity of the invading menisci $v$, as

$$
\Delta P_{l}=\frac{8 \eta v L_{t}}{\bar{r}^{2}}
$$

And

$$
\Delta P_{c}=\frac{2 \sigma \sigma_{0}}{\bar{r}^{2}}
$$

Ref. [58] considering the PSD with mean throat radius $\bar{r}$ and standard deviation $\sigma_{0}$. (In Equation (3), $L_{t}$ denotes the length of a throat). The conditions for capillary fingering are fulfilled, if the capillary number is below $10^{-4}[48,59]$. With the given values for viscosity, surface tension and PSD, this would be achieved if the invasion velocity is below $3.3 \mathrm{~mm} / \mathrm{min}$ (with liquid viscosity of water $\eta=10^{-3} \mathrm{~Pa} \mathrm{~s}$ and surface tension $\sigma=0.073 \mathrm{~N} / \mathrm{m}$ at $20^{\circ} \mathrm{C}$, throat length $L_{t}=50 \mu \mathrm{m}$ and standard deviation $=1.5 \mu \mathrm{m}$ ). This is in good agreement with correlations of the invasion time and current density estimated in [46]. Transition to another invasion regime, e.g., stable displacement or viscous fingering [48] would occur if the invasion velocity would be increased or also if the standard deviation of the throat size would be decreased. Such effects are observed in the research of drying of PNs, where sufficiently narrow PSDs can result in stable, i.e., viscosity-dominated invasion [58]. When viscosity comes into play, the width of the invasion front scales with capillary number. However, in the absence of viscosity, the probability of the throat invasion depends on the PSD. In the limit of identical throat sizes, all throats would be equally selected for invasion. In the case of our simulation, where in a such a limit the selection would not be stochastically distributed but ordered by the throat number, the invasion would always occur in the throat with the lowest number (also refer to Figure 4) wherefore consequently this special situation (i.e., no distribution of throat and pore sizes) could not be simulated with the current algorithm. In contrast, when the throat size distribution becomes broader, the invasion follows the path of the least resistance, which results in a more random distribution of the phase patterns, provided that the throat sizes are randomly distributed. Following [60] and [61], the occupation probability decreases with growing $\Delta r$.

\subsection{Pore Network Simulations of Real Porous Structures}

The above discussions are referred to rather artificial porous structures aiming at a more fundamental understanding of the influence of the pore structure on the invasion behavior. In the following, we would like to compare the results for realistic pore structures, extracted from felt, foam and sintered PTLs. The simulation results are compared to literature values from Arbabi et al. [20]. For this purpose, the PN simulations were repeated with a single-entry point (similar as in Figure 7). In more detail, the invasion starts from a single gas pore while all other surface pores are not connected to the oxygen supply. Simulations for each type of PTL were repeated five times with the PSDs shown in Figure 14. From these simulations, representative patterns, i.e., which were most frequently observed, are shown in Figure 15. It is seen that felt and foam PTL show more constricted patterns, while the sintered PTL allows relatively broad patterns with more gas invasions, which is explained well enough by the assumed PSDs for each type (Figure 14).

It is remarked that the PSDs are usually not provided in literature [20]. Due to this, we have selected a standard deviation of throat width so as to catch the gas-liquid phase distributions found for microfluidic experiments in the literature. The agreement of the simulated and the experimental invasion behavior is very well. Also, the results are in line with the discussion of the impact of PSDs 
above. Namely, the foam exhibits one capillary finger that invades the PN almost straightly. The felt PTL, with a slightly broader PSD (Figure 15), instead reveals a slight widening of the invasion front in horizontal direction. In contrast to that, the sintered PTL allows for a broadening of the invasion front and a significantly higher gas saturation at breakthrough.

In addition to that, it becomes clear from Figure 15 that the effect of liquid clustering occurs in all types of the PTL. The greatest number of isolated liquid clusters is observed in the sintered PTL where the number of invaded pores is higher and the invasion front appears more ramified. In the case of felt and foam PTL, isolated clusters are not seen on the experimental images. This could be because of the small size of the PN and the overall lower number of pore invasions.

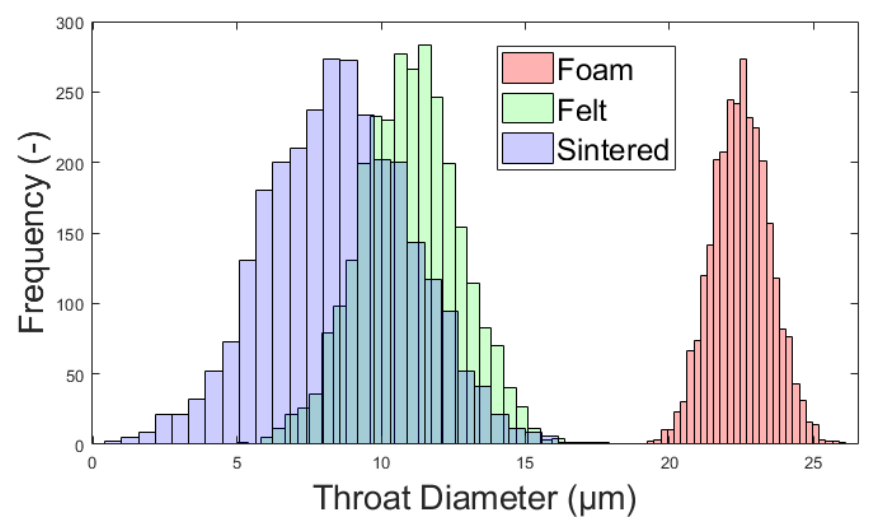

Figure 14. PSDs used for different PTL types with standard deviations: $1.0 \mu \mathrm{m}$ for foam, $1.7 \mu \mathrm{m}$ for felt and $2.5 \mu \mathrm{m}$ for sintered.

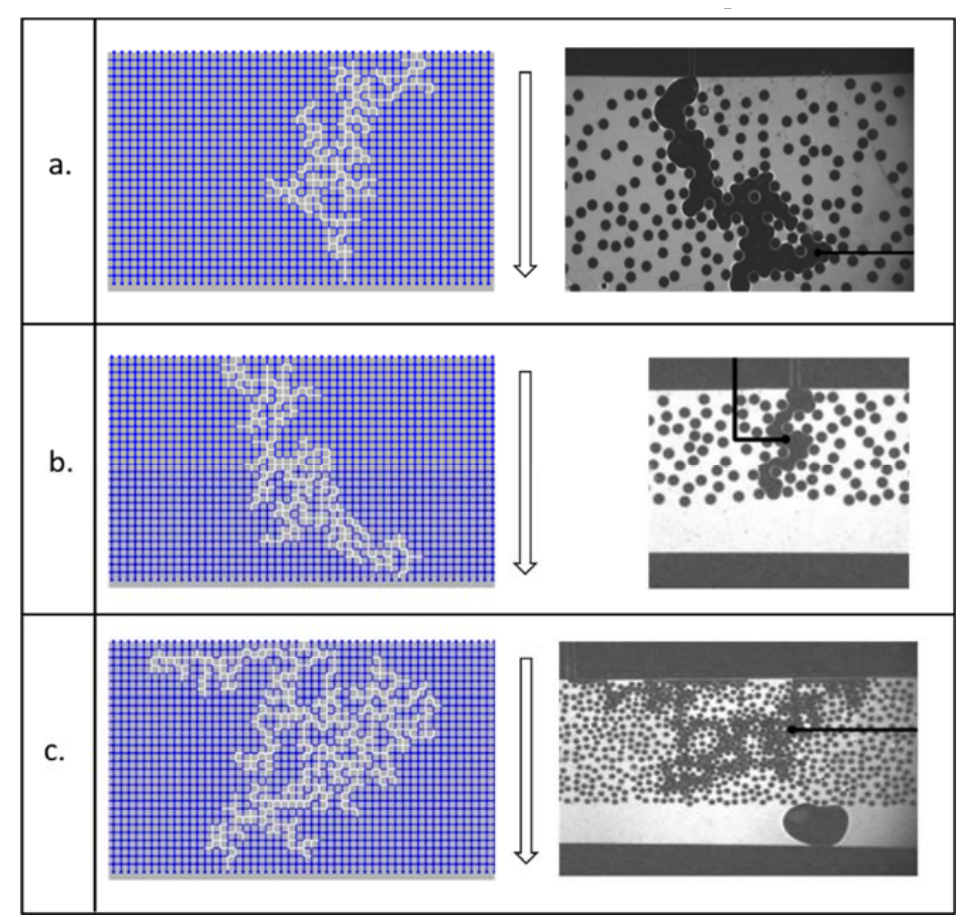

Figure 15. Invasion pattern comparison: (a) foam PTL, (b) felt PTL, (c) sintered PTL (Experimental images from [20] are reprinted with the permission from Elsevier, 2014).

\section{Summary and Conclusions}

In this study, the applicability of PMNs for the simulation of water drainage from PTL was discussed. The PNM applies invasion percolation rules for hydrophilic drainage. It was shown that the PNM can reliably predict the invasion patterns of 2D microfluidic devices related to water electrolysis 
studies. In addition to that, the structure dependence of the invasion process was studied using various types of PTLs (foam, felt, sintered). In agreement with experimental data from literature, we could predict different invasion patterns for the three cases. Felt and foam PTLs showed narrow gas fingers while sintered PTL showed widespread invasion front patterns with a higher number of trapped clusters. This observation matches the theoretical investigations based on a Monte Carlo study of PSDs and invasion probability. Based on this, it could furthermore be shown, that the PSD affects the invasion patterns more significantly than the porosity. More clearly, it was revealed that the PSD could be adjusted independently of the porosity and that this resulted in different invasion patterns. The impact of PSD can also be extended towards porous media in fuel cells.

As a next step, the PN will be further enhanced to replicate the local coordination numbers in real PTLs with non-uniform distribution of pores and throats. The purpose would be to simulate mass transfer within the real structure of porous media rather than in an idealized network. These simulations would then be much closer to reality compared to the ones with a fixed coordination number in the network. The effective transport parameters, e.g., permeability, could also then be extracted by solving mass transfer equations pore by pore in a real structure. It would also be important to study the effect of local temperature changes in the system and liquid flow through corner films. Unsteady changes in the current density could also lead to pressure changes. For this reason, the application of imbibition rules along with drainage will become important.

Author Contributions: Conceptualization, N.V. and T.V.-K.; methodology, N.V.; software, H.A.; validation, H.A.; formal analysis, N.V. and T.V.-K.; investigation, H.A.; resources, N.V. and E.T.; data curation, H.A.; writing-original draft preparation, H.A.; writing-review and editing, N.V.; visualization, H.A.; supervision, N.V. and T.V.-K.; project administration, N.V., T.V.-K. and E.T.; funding acquisition, N.V., T.V.-K. and E.T. All authors have read and agreed to the published version of the manuscript.

Funding: This research received no external funding.

Conflicts of Interest: The authors declare no conflict of interest.

\section{Symbols}

$\begin{array}{ll}L & \text { Distance between nodes } \\ L_{t} & \text { Length of throat } \\ P_{c} & \text { Capillary pressure } \\ P_{l} & \text { Liquid pressure } \\ r_{p} & \text { Pore radius } \\ r_{t} & \text { Throat radius } \\ \bar{r} & \text { Mean radius } \\ v & \text { Velocity of invading menisci } \\ V_{p} & \text { Volume of pore } \\ V_{t} & \text { Volume of throat } \\ z & \text { PTL space coordinate } \\ \eta & \text { Viscosity of liquid phase } \\ \boldsymbol{\theta} & \text { Contact angle } \\ \sigma & \text { Surface tension } \\ \sigma_{0} & \text { Standard deviation } \\ \text { Abbreviations } & \\ \text { Ca } & \text { Capillary number } \\ \text { PN } & \text { Pore network } \\ \text { PNM } & \text { Pore network model } \\ \text { PSD } & \text { Pore size distribution } \\ \text { PTL } & \text { Porous transport layer } \\ \text { Ti } & \text { Titanium } \\ & \end{array}$




\section{References}

1. Das, L.M. Hydrogen-fueled internal combustion engines. In Compendium of Hydrogen Energy; Elsevier: Amsterdam, The Netherlands, 2016; pp. 177-217.

2. Ursua, A.; Gandia, L.M.; Sanchis, P. Hydrogen Production From Water Electrolysis: Current Status and Future Trends. Proc. IEEE 2012, 100, 410-426. [CrossRef]

3. Balat, M. Potential importance of hydrogen as a future solution to environmental and transportation problems. Int. J. Hydrog. Energy 2008, 33, 4013-4029. [CrossRef]

4. Chen, Y.; Hu, X.; Liu, J. Life Cycle Assessment of Fuel Cell Vehicles Considering the Detailed Vehicle Components: Comparison and Scenario Analysis in China Based on Different Hydrogen Production Schemes. Energies 2019, 12, 3031. [CrossRef]

5. Elgowainy, A.; Gaines, L.; Wang, M. Fuel-cycle analysis of early market applications of fuel cells: Forklift propulsion systems and distributed power generation. Int. J. Hydrog. Energy 2009, 34, 3557-3570. [CrossRef]

6. Felder, F.A.; Hajos, A. Using Restructured Electricity Markets in the Hydrogen Transition: The PJM Case. Proc. IEEE 2006, 94, 1864-1879. [CrossRef]

7. Shaw, S.; Peteves, E. Exploiting synergies in European wind and hydrogen sectors: A cost-benefit assessment. Int. J. Hydrog. Energy 2008, 33, 3249-3263. [CrossRef]

8. Carmo, M.; Fritz, D.L.; Mergel, J.; Stolten, D. A comprehensive review on PEM water electrolysis. Int. J. Hydrog. Energy 2013, 38, 4901-4934. [CrossRef]

9. Zoulias, E.I.; Glockner, R.; Lymberopoulos, N.; Tsoutsos, T.; Vosseler, I.; Gavalda, O.; Mydske, H.J.; Taylor, P. Integration of hydrogen energy technologies in stand-alone power systems analysis of the current potential for applications. Renew. Sustain. Energy Rev. 2006, 10, 432-462. [CrossRef]

10. Degiorgis, L.; Santarelli, M.; Calì, M. Hydrogen from renewable energy: A pilot plant for thermal production and mobility. J. Power Sources 2007, 171, 237-246. [CrossRef]

11. Kosonen, A.; Koponen, J.; Huoman, K.; Ahola, J.; Ruuskanen, V.; Ahonen, T.; Graf, T. Optimization strategies of PEM electrolyser as part of solar PV system. In Proceedings of the IEEE 18th European Conference on Power Electronics and Applications (EPE'16 ECCE Europe), Karlsruhe, Germany, 5-9 September 2016; pp. 1-10.

12. Dedigama, I.; Angeli, P.; Ayers, K.; Robinson, J.B.; Shearing, P.R.; Tsaoulidis, D.; Brett, D.J.L. In situ diagnostic techniques for characterisation of polymer electrolyte membrane water electrolysers-Flow visualisation and electrochemical impedance spectroscopy. Int. J. Hydrog. Energy 2014, 39, 4468-4482. [CrossRef]

13. Nieminen, J.; Dincer, I.; Naterer, G. Comparative performance analysis of PEM and solid oxide steam electrolysers. Int. J. Hydrog. Energy 2010, 35, 10842-10850. [CrossRef]

14. Grigoriev, S.A.; Millet, P.; Volobuev, S.A.; Fateev, V.N. Optimization of porous current collectors for PEM water electrolysers. Int. J. Hydrog. Energy 2009, 34, 4968-4973. [CrossRef]

15. Ito, H.; Maeda, T.; Nakano, A.; Hwang, C.M.; Ishida, M.; Kato, A.; Yoshida, T. Experimental study on porous current collectors of PEM electrolyzers. Int. J. Hydrog. Energy 2012, 37, 7418-7428. [CrossRef]

16. Mo, J.; Kang, Z.; Yang, G.; Li, Y.; Retterer, S.T.; Cullen, D.A.; Toops, T.J.; Bender, G.; Pivovar, B.S.; Green, J.B., Jr.; et al. In situ investigation on ultrafast oxygen evolution reactions of water splitting in proton exchange membrane electrolyzer cells. J. Mater. Chem. A 2017, 5, 18469-18475. [CrossRef]

17. Lee, C.H.; Banerjee, R.; Arbabi, F.; Hinebaugh, J.; Bazylak, A. Porous Transport Layer Related Mass Transport Losses in Polymer Electrolyte Membrane Electrolysis: A Review. In Proceedings of the ASME 14th International Conference on Nanochannels, Microchannels, and Minichannels, Washington, DC, USA, 10-14 July 2016. [CrossRef]

18. Ito, H.; Maeda, T.; Nakano, A.; Kato, A.; Yoshida, T. Influence of pore structural properties of current collectors on the performance of proton exchange membrane electrolyzer. Electrochim. Acta 2013, 100, 242-248. [CrossRef]

19. Lee, C.; Hinebaugh, J.; Banerjee, R.; Chevalier, S.; Abouatallah, R.; Wang, R.; Bazylak, A. Influence of limiting throat and flow regime on oxygen bubble saturation of polymer electrolyte membrane electrolyzer porous transport layers. Int. J. Hydrog. Energy 2017, 42, 2724-2735. [CrossRef]

20. Arbabi, F.; Kalantarian, A.; Abouatallah, R.; Wang, R.; Wallace, J.S.; Bazylak, A. Feasibility study of using microfluidic platforms for visualizing bubble flows in electrolyzer gas diffusion layers. J. Power Sour. 2014, 258, 142-149. [CrossRef] 
21. Nie, J.; Chen, Y. Numerical modeling of three-dimensional two-phase gas-liquid flow in the flow field plate of a PEM electrolysis cell. Int. J. Hydrog. Energy 2010, 35, 3183-3197. [CrossRef]

22. Ito, H.; Maeda, T.; Nakano, A.; Hasegawa, Y.; Yokoi, N.; Hwang, C.M.; Ishida, M.; Kato, A.; Yoshida, T. Effect of flow regime of circulating water on a proton exchange membrane electrolyzer. Int. J. Hydrog. Energy 2010, 35, 9550-9560. [CrossRef]

23. Badwal, S.P.S.; Giddey, S.; Munnings, C. Emerging technologies, markets and commercialization of solid-electrolytic hydrogen production. WIRE Energy Environ. 2018, 7, e286. [CrossRef]

24. Babic, U.; Suermann, M.; Büchi, F.N.; Gubler, L.; Schmidt, T.J. Critical Review-Identifying Critical Gaps for Polymer Electrolyte Water Electrolysis Development. J. Electrochem. Soc. 2017, 164, F387-F399. [CrossRef]

25. Yigit, T.; Selamet, O.F. Mathematical modeling and dynamic Simulink simulation of high-pressure PEM electrolyzer system. Int. J. Hydrog. Energy 2016, 41, 13901-13914. [CrossRef]

26. Kang, Z.; Mo, J.; Yang, G.; Retterer, S.T.; Cullen, D.A.; Toops, T.J.; Green, J.B., Jr.; Mench, M.M.; Zhang, F.-Y. Investigation of thin/well-tunable liquid/gas diffusion layers exhibiting superior multifunctional performance in low-temperature electrolytic water splitting. Energy Environ. Sci. 2017, 10, 166-175. [CrossRef]

27. Sadeghi Lafmejani, S.; Olesen, A.C.; Kaer, S.K. Analysing Gas-Liquid Flow in PEM Electrolyser Micro-Channels. ECS Trans. 2016, 75, 1121-1127. [CrossRef]

28. Selamet, O.F.; Pasaogullari, U.; Spernjak, D.; Hussey, D.S.; Jacobson, D.L.; Mat, M. In Situ Two-Phase Flow Investigation of Proton Exchange Membrane (PEM) Electrolyzer by Simultaneous Optical and Neutron Imaging. ECS Trans. 2011, 41, 349-362.

29. Ojong, E.T.; Kwan, J.T.H.; Nouri-Khorasani, A.; Bonakdarpour, A.; Wilkinson, D.P.; Smolinka, T. Development of an experimentally validated semi-empirical fully-coupled performance model of a PEM electrolysis cell with a 3-D structured porous transport layer. Int. J. Hydrog. Energy 2017, 42, 25831-25847. [CrossRef]

30. Abdol Rahim, A.H.; Tijani, A.S.; Kamarudin, S.K.; Hanapi, S. An overview of polymer electrolyte membrane electrolyzer for hydrogen production: Modeling and mass transport. J. Power Sour. 2016, 309, $56-65$. [CrossRef]

31. Aubras, F.; Deseure, J.; Kadjo, J.-J.A.; Dedigama, I.; Majasan, J.; Grondin-Perez, B.; Chabriat, J.-P.; Brett, D.J.L. Two-dimensional model of low-pressure PEM electrolyser: Two-phase flow regime, electrochemical modelling and experimental validation. Int. J. Hydrog. Energy 2017, 42, 26203-26216. [CrossRef]

32. Olesen, A.C.; Rømer, C.; Kær, S.K. A numerical study of the gas-liquid, two-phase flow maldistribution in the anode of a high pressure PEM water electrolysis cell. Int. J. Hydrog. Energy 2016, 41, 52-68. [CrossRef]

33. Lee, J.K.; Lee, C.; Bazylak, A. Pore network modelling to enhance liquid water transport through porous transport layers for polymer electrolyte membrane electrolyzers. J. Power Sour. 2019, 437, 226910. [CrossRef]

34. Zhang, H.; Lin, G.; Chen, J. Evaluation and calculation on the efficiency of a water electrolysis system for hydrogen production. Int. J. Hydrog. Energy 2010, 35, 10851-10858. [CrossRef]

35. Hwang, C.M.; Ishida, M.; Ito, H.; Maeda, T.; Nakano, A.; Hasegawa, Y.; Yokoi, N.; Kato, A.; Yoshida, T. Influence of properties of gas diffusion layers on the performance of polymer electrolyte-based unitized reversible fuel cells. Int. J. Hydrog. Energy 2011, 36, 1740-1753. [CrossRef]

36. Han, B.; Mo, J.; Kang, Z.; Yang, G.; Barnhill, W.; Zhang, F.-Y. Modeling of two-phase transport in proton exchange membrane electrolyzer cells for hydrogen energy. Int. J. Hydrog. Energy 2017, 42, 4478-4489. [CrossRef]

37. Lee, C.; Zhao, B.; Abouatallah, R.; Wang, R.; Bazylak, A. Compressible-Gas Invasion into Liquid-Saturated Porous Media: Application to Polymer-Electrolyte-Membrane Electrolyzers. Phys. Rev. Appl. 2019, 11, 054029. [CrossRef]

38. Mo, J.; Dehoff, R.R.; Peter, W.H.; Toops, T.J.; Green, J.B.; Zhang, F.-Y. Additive manufacturing of liquid/gas diffusion layers for low-cost and high-efficiency hydrogen production. Int. J. Hydrog. Energy 2016, 41, 3128-3135. [CrossRef]

39. Lettenmeier, P.; Kolb, S.; Sata, N.; Fallisch, A.; Zielke, L.; Thiele, S.; Gago, A.S.; Friedrich, K.A. Comprehensive investigation of novel pore-graded gas diffusion layers for high-performance and cost-effective proton exchange membrane electrolyzers. Energy Environ. Sci. 2017, 10, 2521-2533. [CrossRef]

40. Kang, Z.; Mo, J.; Yang, G.; Li, Y.; Talley, D.A.; Retterer, S.T.; Cullen, D.A.; Toops, T.J.; Brady, M.P.; Bender, G.; et al. Thin film surface modifications of thin/tunable liquid/gas diffusion layers for high-efficiency proton exchange membrane electrolyzer cells. Appl. Energy 2017, 206, 983-990. [CrossRef] 
41. Schuler, T.; Schmidt, T.J.; Büchi, F.N. Polymer Electrolyte Water Electrolysis: Correlating Performance and Porous Transport Layer Structure: Part II. Electrochemical Performance Analysis. J. Electrochem. Soc. 2019, 166, F555-F565. [CrossRef]

42. Prat, M.; Agaësse, T. Thin Porous Media. In Handbook of Porous Media, 3rd ed.; Vafai, K., Ed.; CRC Press: Boca Raton, FL, USA, 2015; pp. 89-112.

43. Raeini, A.Q.; Yang, J.; Bondino, I.; Bultreys, T.; Blunt, M.J.; Bijeljic, B. Validating the Generalized Pore Network Model Using Micro-CT Images of Two-Phase Flow. Transp. Porous. Med. 2019, 130, 405-424. [CrossRef]

44. Tranter, T.G.; Gostick, J.T.; Burns, A.D.; Gale, W.F. Pore Network Modeling of Compressed Fuel Cell Components with OpenPNM. Fuel Cells 2016, 16, 504-515. [CrossRef]

45. Metzger, T. A personal view on pore network models in drying technology. Dry. Technol. 2019, 37, 497-512. [CrossRef]

46. Vorhauer, N.; Altaf, H.; Tsotsas, E.; Vidakovic-Koch, T. Pore Network Simulation of Gas-Liquid Distribution in Porous Transport Layers. Processes 2019, 7, 558. [CrossRef]

47. Joekar-Niasar, V.; Hassanizadeh, S.M. Analysis of Fundamentals of Two-Phase Flow in Porous Media Using Dynamic Pore-Network Models: A Review. Crit. Rev. Environ. Sci. Technol. 2012, 42, 1895-1976. [CrossRef]

48. Sinha, P.K.; Wang, C.-Y. Pore-network modeling of liquid water transport in gas diffusion layer of a polymer electrolyte fuel cell. Electrochim. Acta 2007, 52, 7936-7945. [CrossRef]

49. Sinha, P.K.; Wang, C.-Y. Liquid water transport in a mixed-wet gas diffusion layer of a polymer electrolyte fuel cell. Chem. Eng. Sci. 2008, 63, 1081-1091. [CrossRef]

50. Lee, K.-J.; Nam, J.H.; Kim, C.-J. Pore-network analysis of two-phase water transport in gas diffusion layers of polymer electrolyte membrane fuel cells. Electrochim. Acta 2009, 54, 1166-1176. [CrossRef]

51. Bultreys, T.; Singh, K.; Raeini, A.Q.; Ruspini, L.C.; Øren, P.-E.; Berg, S.; Rücker, M.; Bijeljic, B.; Blunt, M.J. Verifying pore network models of imbibition in rocks using time-resolved synchrotron imaging. EarthArXiv 2019. [CrossRef]

52. Vorhauer, N.; Tran, Q.T.; Metzger, T.; Tsotsas, E.; Prat, M. Experimental Investigation of Drying in a Model Porous Medium: Influence of Thermal Gradients. Dry. Technol. 2013, 31, 920-929. [CrossRef]

53. Metzger, T.; Irawan, A.; Tsotsas, E. Influence of pore structure on drying kinetics: A pore network study. AIChE J. 2007, 53, 3029-3041. [CrossRef]

54. Al-Futaisi, A.; Patzek, T.W. Extension of Hoshen-Kopelman algorithm to non-lattice environments. Phys. A Stat. Mech. Appl. 2003, 321, 665-678. [CrossRef]

55. Hoshen, J. On the application of the enhanced Hoshen-Kopelman algorithm for image analysis. Pattern Recognit. Lett. 1998, 19, 575-584. [CrossRef]

56. Xu, B.; Yortsos, Y.C.; Salin, D. Invasion percolation with viscous forces. Phys. Rev. E 1998, 57, 739-751. [CrossRef]

57. Lenormand, R. Liquids in porous media. J. Fluid Mech. 1990, 2, SA79-SA88. [CrossRef]

58. Metzger, T.; Tsotsas, E.; Prat, M. Pore-Network Models: A Powerful Tool to Study Drying at the Pore Level and Understand the Influence of Structure on Drying Kinetics. In Modern Drying Technology: Tools at Different Scales; Tsotsas, E., Mujumdar, A.S., Eds.; Wiley: Weinheim, Germany, 2007; pp. 57-102.

59. Lenormand, R.; Touboul, E.; Zarcone, C. Numerical models and experiments on immiscible displacements in porous media. J. Fluid Mech. 1988, 189, 165-187. [CrossRef]

60. Prat, M.; Bouleux, F. Drying of capillary porous media with a stabilized front in two dimensions. Phys. Rev. E 1999, 60, 5647-5656. [CrossRef]

61. Vorhauer, N.; Tsotsas, E.; Prat, M. Temperature gradient induced double stabilization of the evaporation front within a drying porous medium. Phys. Rev. Fluids 2018, 3, 217. [CrossRef]

(C) 2020 by the authors. Licensee MDPI, Basel, Switzerland. This article is an open access article distributed under the terms and conditions of the Creative Commons Attribution (CC BY) license (http://creativecommons.org/licenses/by/4.0/). 